\title{
Trabalhonecessário
}

Issn: 1808 - 799X

ano 11, no $17-2013$

\section{ORGANIZAÇÃO DO TRABALHO PEDAGÓGICO E ENSINO INTEGRADO}

\author{
Ronaldo Marcos de Lima Araujo ${ }^{1}$ \\ Ana Maria Rayol Costa ${ }^{2}$ \\ Manuela Tavares Santos ${ }^{3}$
}

\section{RESUMO:}

Trata este artigo de orientações para a organização do trabalho pedagógico para o ensino integrado, compreendido como um conjunto de estratégias mediadoras dos processos de ensino e de aprendizagem com vistas ao enfretamento da fragmentação do saber escolar e a instrumentalizar a luta pelo exercício da liberdade. Problematiza a ideia de que soluções apenas didáticas são capazes de resolver o problema de operacionalização da organização curricular para a integração. Toma a Filosofia da Práxis como referência teórica e metodológica e a pesquisa bibliográfica como recurso de pesquisa. Afirma que a contextualização, a interdisciplinaridade e o compromisso com as transformações sociais constituem-se como ideias de referência para a organização didática a partir das quais podem ser organizadas práticas pedagógicas que se querem orientadas pela ideia de integração. Sustenta ainda que decisivo para este intento é o compromisso ético, político e pedagógico com a formação ampla dos trabalhadores e com o projeto de transformação social. Ao concluir afirma a inexistência de um único método capaz de operacionalizar o ensino integrado e sustenta a flexibilidade nas formas de organização do trabalho pedagógico como condição para a eficiência dos projetos educacionais integradores.

Palavras chaves: ensino médio - educação profissional - ensino integrado práticas pedagógicas - organização curricular.

\footnotetext{
${ }^{1}$ Professor do Instituto de Educação da UFPA (graduação e pós). Doutor em Educação pela UFMG. Pesquisador do CNPq. Emeio: rlima@ufpa.br.

${ }^{2}$ Professora da Rede Estadual de Ensino do Pará. Mestre em Educação pela Universidade Federal do Pará. Emeio: anaraioldavi@ig.com.br.

${ }^{3}$ Pedagoga de Rede Municipal de Ensino de Belém. Mestre em Educação peã Universidade Federal do Pará. Emeio: manuela.05@hotmail.com.
} 


\section{Trabalhonecessário}

Issn: 1808 - 799X

ano 11, no $17-2013$

\section{ORGANIZACIÓN DEL TRABAJO PEDAGÓGICO Y ENSEÑANZA INTEGRADA}

\section{RESUMEN:}

Trata este artículo de orientaciones para la organización del trabajo pedagógico para la enseñanza integrada, comprendida como un conjunto de estrategias mediadoras de los procesos de enseñanza y aprendizaje con el fin de enfrentar la fragmentación del saber escolar y de instrumentalizar la lucha por el ejercicio de la libertad. Problematiza la idea de que la aplicación de soluciones didácticas consigue resolver el problema de la operacionalización de la organización curricular para la integración. Toma la Filosofía de la Praxis como referencia teórica y metodológica y la investigación bibliográfica como recurso de pesquisa. Afirma que la contextualización, la interdisciplinaridad y el compromiso con las transformaciones sociales se constituyen como ideas de referencia para la organización didáctica a partir de la que pueden organizarse prácticas pedagógicas que se orientan en la idea de integración. Sostiene, además, que es decisivo para este intento un compromiso ético, político y pedagógico con la formación amplia de los trabajadores y con el proyecto de transformación social. Al concluir, afirma que no existe un único método capaz de operacionalizar la enseñanza integrada y sostiene la flexibilidad en las formas de organización del trabajo pedagógico como condición para la eficiencia de los proyectos educativos integradores.

Palabras llave: enseñanza media - educación profesional - enseñanza integrada - prácticas pedagógicas - organización curricular. 


\title{
Trabalhonecessário
}

Issn: 1808 - 799X

ano 11, no $17-2013$

\section{PEDAGOGICAL WORK ORGANIZATION AND INTEGRATED TEACHING}

\begin{abstract}
:
This article discusses orientations for the organization of educational work for the integrated education, understood as a set of strategies that mediate the processes of teaching and learning with a view to coping fragmentation of school knowledge and give the tools for the struggle for the exercising of freedom. It questions the idea that only didactical solutions are able to solve the problem of operationalization of curricular organization for integration. Takes the Philosophy of Praxis as theoretical and methodological references and literature as a resource for research. States that contextualization, interdisciplinarity and commitment to social change are the reference ideas for the didactical organization from which can be organized pedagogical practices that want to be guided by the idea of integration. It further maintains that for this intent is critical the ethical, political and educational commitment with ample training of workers and with the project of social transformation. At the conclusion asserts that there is no single method to operationalize the integrated teaching and sustains flexibility in the forms of organization of educational work as a condition for the effectiveness of the integrated education projects.
\end{abstract}

KEYWORDS: High School - vocational education - Integrated Teaching Pedagogical practices - curriculum organization. 


\section{Trabalhonecessário}

Issn: 1808 - 799X

ano 11 , no $17-2013$

\section{Considerações iniciais:}

Neste artigo resgatamos algumas orientações para a organização do trabalho pedagógico, na perspectiva do ensino integrado, aquele compreendido como um conjunto de estratégias mediadoras dos processos de ensino e de aprendizagem com vistas a instrumentalizar a luta pelo exercício da liberdade.

Temos como suposto que são várias as possibilidades de arranjos pedagógicos e curriculares que favoreçam as práticas pedagógicas orientadas pela ideia de integração e que são diferenciados os elementos de integração do ensino e da aprendizagem. A escolha por um arranjo depende de várias varáveis como as condições concretas de realização da formação, o conhecimento e a maturidade profissional do professor, o perfil da turma e o tempo disponível, mas, decisivo é o compromisso docente com as ideias de formação integrada e de transformação social.

O ponto de partida para as diferentes construções destes arranjos é o reconhecimento de que a fragmentação do saber é o principal problema a ser enfrentado na organização dos conteúdos formativos em direção ao ensino integrado.

Alertamos, entretanto, para a necessária recusa a existência de um único método para o ensino integrado e procuramos sustentar a flexibilidade nas formas de organização do trabalho pedagógico como condição para a eficiência dos projetos educacionais integradores. A flexibilidade, por sua vez, requer o permanente desenvolvimento da "criatividade organizativa" dos diferentes agentes de ensino (gestores, técnicos educacionais e professores).

Tomamos a contextualização, a interdisciplinaridade e o compromisso com as transformações sociais como ideias de referência para a organização didática a partir das quais podem ser organizadas práticas pedagógicas que se 


\section{Trabalhonecessário}

Issn: 1808 - 799X

ano 11, no $17-2013$

querem orientadas pela ideia de integração, decisivo, entretanto, é o compromisso ético, político e pedagógico com a formação ampla dos trabalhadores e com o projeto de transformação social. Neste texto, além de recuperar estas ideias de referência, procuramos considerar algumas possibilidades concretas de organização do trabalho pedagógico que oferecem condições potenciais para a implementação de práticas de integração. Todas as considerações aqui feitas levam em conta, em particular, a realidade das escolas de ensino médio e técnico do Brasil, mas não se reduzem a estas já que o necessário enfrentamento à fragmentação do saber é uma necessidade para todas as etapas da educação formal.

Neste texto discutimos, de início, a concepção de currículo integrado e algumas ideias que devem servir de referencia para a sua organização na perspectiva da integração, depois algumas estratégias de organização curricular destacando alguns arranjos de organização curricular que podem favorecer a integração, tais como o sistema de complexos, a pedagogia da alternância e a pedagogia de projetos, bem como a proposta contida no PROEJA.

\section{Possibilidades de desenho curricular para o ensino integrado:}

O currículo integrado vem ganhando destaque nos debates educacionais contemporâneos brasileiros, entre outros motivos, pelo fato de ter ganhado corpo em setores do Governo Federal, em alguns governos estaduais e entre alguns pesquisadores da área de trabalho e educação a proposta de construção de um ensino médio integrado ${ }^{4}$. Também porque diferentes

\footnotetext{
${ }^{4}$ Sobre isso recomendamos a leitura de Frigotto, Ciavatta e Ramos (2005).
} 


\section{Trabalhonecessário}

Issn: 1808 - 799X

ano 11, no $17-2013$

organizações de trabalhadores do Brasil, especialmente as vinculadas aos trabalhadores rurais, tem colocado em pauta projetos educacionais que requerem um tipo de formação que enfrente a tradicional fragmentação do ensino que marca a educação escolar brasileira, que considere os saberes dos trabalhadores e que assegure a qualificação ampla e duradoura dos trabalhadores na perspectiva da transformação social. Assim, as propostas educativas que visem uma ação pedagógica integrada são colocadas como uma necessidade e como uma possibilidade de qualificação da educação escolar ofertada no âmbito do ensino médio no Brasil.

Apesar de considerarmos que o ensino integrado não deva ser resumido a um projeto pedagógico, menos ainda a um procedimento didático ou a um tipo específico de desenho curricular, estas dimensões são verdadeiras e necessariamente devem ser objeto da preocupação e do labor dos estudiosos e educadores que se assumem comprometidos com emancipação social. Por isso assumimos aqui o desafio de pensar possibilidades de organização curricular que favoreçam práticas pedagógicas de integração.

Diferentes são as formas de se pensar os conteúdos necessários para a formação de crianças, jovens e adultos capazes de desenvolver a sua capacidade de, autonomamente, interpretar e agir sobre a realidade. Diferentes também são as possibilidades de organizar os conteúdos necessários para tal. Mas o fundamental é o compromisso com a formação ampla dos trabalhadores e a articulação dos processos de formação com o projeto ético-político de transformação social. Tendo em vistas esses dois pressupostos as formas de reorganização curricular devem ser experimentadas e avaliadas, considerando que não há uma única forma e nem uma forma mais correta que outra para a efetivação de um currículo integrado, mas que elas sempre favorecem mais ou menos a integração.

TrabalhoNecessário - www.uff.br/trabalhonecessario; Ano 11, № 17/2013. 


\section{Trabalhonecessário}

Issn: 1808 - 799X

ano 11, no $17-2013$

O currículo, assim como a escola, é espaço de contradição, apesar de reproduzir as estruturas existentes, é "correia de transmissão da ideologia oficial" e, ao mesmo tempo, uma ameaça à ordem estabelecida por oferecer a possibilidade de contribuir para a libertação (GADOTTI, 1992, p. 150). Constitui-se, portanto, em um espaço de luta entre as classes dominantes e as subalternas, refletindo a "exploração e a luta contra a exploração".

Considerado assim o currículo constitui-se como uma arena política de ideologia, poder e cultura. Consiste em um campo ideológico por produzir e transmitir uma visão de mundo vinculado aos interesses dos grupos sociais, por meio das práticas educativas. É um espaço de expressão das relações sociais de poder, visto que se constitui e, ao mesmo tempo, resulta da relação entre as classes sociais; é uma área de conflitos de cultura de classes, em que se transmite a cultura oficial e se produz a cultura contestada. Portanto, é um conjunto de ações políticas, determinadas social e historicamente (SILVA; MOREIRA, 2005).

O ensino médio público no Brasil e, em particular a educação profissional, tem a sua organização curricular marcada por formas curriculares instrumentais e promotoras de um tipo humano conformado, política e pedagogicamente. Os projetos pedagógicos seriam pensados em função daquilo que se revelasse imediatamente útil e com esta lógica seriam organizados os currículos.

Machado (2009: 02) entende assim o currículo integrado:

É a concepção e a experimentação de hipóteses de trabalho e de propostas de ação didática que tenham, como eixo, a abordagem relacional de conteúdos tipificados estruturalmente como diferentes, considerando que esta diferenciação não pode, a rigor, ser tomada como absoluta ainda que haja especificidades que devem ser reconhecidas. Com relação ao objeto deste artigo, são os conteúdos classificados

TrabalhoNecessário - www.uff.br/trabalhonecessario; Ano 11, № 17/2013. 


\section{Trabalhonecessário}

Issn: 1808 - 799X

ano 11, no $17-2013$ como gerais ou básicos e os conteúdos nomeados como profissionais ou
tecnológicos.

Assumimos aqui alguns princípios orientadores para a organização curricular na perspectiva da integração e consideramos que tais princípios não remetem a uma única fórmula de organização curricular, pelo contrário, permitem diferentes possibilidades de projetos formativos comprometidos com a ideia de integração:

- Contextualização. Pressupõe, na perspectiva aqui trabalhada, a íntima articulação dos conteúdos formativos com a realidade social e com os projetos políticos dos trabalhadores e de suas organizações sociais. Pistrak (2000) defendia que a realidade seria a referência para a organização das disciplinas escolares e que o objetivo da escola deva ser o de estudar a realidade atual. Esta se constituiria, pois, como ponto de partida para os currículos integrados e a realidade social transformada como ponto de chegada. As disciplinas servindo a este fim e os métodos desenvolvendo nos jovens a "intuição marxista", capaz de tornar possível a identificação da essência contraditória (a luta de classes) desta "realidade atual".

- Interdisciplinaridade. Compreendida como o princípio da máxima exploração das potencialidades de cada ciência, da compreensão dos seus limites, mas, acima de tudo, como o princípio da diversidade e da criatividade (ETGES apud BIANCHETTI, 1995). Para este autor, a interdisciplinaridade não toma a fragmentação disciplinar como uma patologia, do mesmo modo, a parceria não é assumida como sinônimo de interdisciplinaridade. Bianchetti (1995) considera que a transdiciplinaridade também pode ser um ato individual de 


\section{Trabalhonecessário}

Issn: 1808 - 799X

ano 11, no $17-2013$

estabelecimento de relação entre as disciplinas e que o conceito de interdisciplinaridade pressupõe que é na totalidade dinâmica que os construtos particulares se fazem verdade. Para Pistrak (2000) a dificuldade da ação interdisciplinar é que cada disciplina toma seus objetivos específicos como os mais importantes, ao invés de subordinarse a um objetivo geral já que, na escola, cada ciência deve ser ensinada apenas como meio de conhecer e de transformar a realidade de acordo com os objetivos gerais da escola (PISTRAK, 2000, p. 119).

- Teleologia. Elemento que diferencia a práxis marxista da filosofia pragmática que busca vincular os processos formativos com demandas imediatas e pontuais. Dewey (1936), filósofo pragmático que propôs o progressivismo educacional, via como impossível "a associação entre processos formativos com ideias de um futuro distante" e subordinava os conteúdos de ensino ao imediato, dando-lhes um sentido prático utilitário, promovendo a conformação. Para tanto, propunha que os processos formativos fossem estruturados sobre os interesses e as realidades dos alunos, considerados individualmente. Na perspectiva aqui assumida (marxista) a ação pedagógica é tomada como ação material, que subordina os conteúdos formativos aos objetivos de transformação social, visando a produção, portanto, da emancipação. Em tal perspectiva a ação (pedagógica) material corresponde a "interesses sociais e que, considerada do ponto de vista histórico-social, não é apenas produção de uma realidade material, mas sim criação e desenvolvimento incessantes da realidade humana" (VÁZQUEZ, 1968, p. 213). 


\section{Trabalhonecessário}

Issn: 1808 - 799X

ano 11, no $17-2013$

Tendo como referência as ideias de contextualização, interdisciplinaridade e teleologia, propomos pensar as estratégias de organização dos conteúdos, na perspectiva do ensino integrado.

\section{Estratégias de organização curricular:}

Para o ensino integrado a organização curricular deve envolver um conjunto de saberes, de diferentes tipos, selecionados e organizados deliberadamente em função da necessária formação ampla dos alunos e da emancipação social da classe trabalhadora.

A fragmentação do saber (saberes teóricos $X$ saberes práticos, saberes tradicionais $X$ saberes científicos, teoria $X$ prática) é o principal problema a ser enfrentado na organização dos conteúdos formativos em direção ao ensino integrado, pois isto dificulta a formação de uma compreensão ampla da realidade. Isso não significa, entretanto, que a organização disciplinar esteja inviabilizada. Se a fragmentação do saber tem sido associado aos currículos disciplinares, o fim das disciplinas não assegura, por si, a formação integrada.

A organização curricular coerente com o projeto de ensino integrado tem várias possibilidades, uma delas é a própria organização por disciplinas, ao se fazer um recorte do real e aprofundar conceitos, articulando a atividades integradoras (interdisciplinares), como forma de vivenciar e simular a realidade, tendo como objetivo a compreensão entre a relação parte-totalidade (SANTOMÉ, 1998).

Como forma de minimizar os prejuízos decorrentes de um tipo de organização fragmentadora do saber diferentes propostas de organização do currículo têm sido apresentadas, algumas delas eliminando as disciplinas escolares. São propostas que tratam da aprendizagem baseada em: 


\section{Trabalhonecessário}

Issn: 1808 - 799X

ano 11, no $17-2013$

problemas, centros de interesses, projetos, complexos temáticos, entre outras. Apesar de potenciais vantagens que essas metodologias trazem ao se aproximarem mais os conhecimentos escolares dos científicos, também existem riscos e fragilidades que precisam ser consideradas no planejamento de ensino e no diálogo entre os educadores.

Não é o fato de os currículos serem disciplinares ou não que vai determinar o conteúdo integrador ou não da organização curricular, apesar de reconhecermos que há formas que favorecem mais ou menos a integração de saberes.

As metodologias não disciplinares, por exemplo, buscam romper com a centralidade das disciplinas nos currículos e substituí-las por elementos globalizadores e que abranjam a complexidade das relações existentes entre os ramos da ciência no mundo real.

Pistrak (2009), dialogando com os progressivistas de seu tempo, defendia a necessidade das disciplinas, para ele deve-se estudar a vida, a realidade, não fora das disciplinas, mas através das disciplinas escolares. As disciplinas escolares, as bases da ciência, devem ser instrumentos para 0 estudo ativo da vida e sua transformação (Pistrak, apud Freitas, 2009: 49 grifos do autor).

Considerando a tradição escolar brasileira, concordamos com as propostas voltadas para o currículo do Ensino Médio, em geral, e técnico, em particular, baseadas em metodologias mistas, como demonstra SANTOMÉ (1998), as quais, para este autor, são desenvolvidas em pelo menos dois espaços e tempos: um voltado para as denominadas atividades integradoras e outro destinado ao aprofundamento conceitual no interior das disciplinas.

Para isto, é necessário que tanto as disciplinas quanto as atividades integradoras sejam construídas e seus conteúdos definidos a partir das 


\section{Trabalhonecessário}

Issn: 1808 - 799X

ano 11 , no $17-2013$

possibilidades de interelações entre os eixos norteadores do Ensino

Integrado, que podem ser definidos para o ensino médio brasileiro como trabalho, ciência, tecnologia e cultura.

O trabalho compreendido como realização humana inerente ao ser (sentido ontológico) e como prática econômica (sentido histórico associado ao modo de produção); a ciência compreendida como os conhecimentos produzidos pela humanidade que possibilita o contraditório avanço das forças produtivas; a tecnologia é uma extensão das capacidades humanas, é transformação da ciência em força produtiva, e, em função de seu caráter social e histórico, portanto, jamais neutro, incorpora os antagonismos sociais em seu processo de produção e redistribuição; a cultura, que corresponde às expressões materiais e simbólicas e aos valores éticos e estéticos que orientam os comportamentos e as normas de conduta de uma sociedade (Brasil, 2013: p.16).

Entretanto, para que isto ocorra, mas evitando que se caia no reducionismo curricular, é importante que o corpo técnico e docente se aproprie da concepção e dos princípios do ensino integrado, com vistas à organização efetiva e significativa dos tempos e espaços de atuação, para garantir que o planejamento possa ser materializado, acompanhado e avaliado.

Assim sendo, a cada período letivo as atividades integradoras podem ser planejadas a partir das relações entre situações reais existentes nas práticas sociais concretas (ou simulações) e os conteúdos das disciplinas, tendo como fio condutor as conexões entre o trabalho e as demais dimensões acima evidenciadas (SANTOMÉ, 1988).

Pistrak (2009) propunha para a escola socialista a organização curricular por complexos, que não abandonava o uso das disciplinas, mas que Ihes dava sentido.

Pelo complexo, compreendido corretamente, se exige que, trabalhando em cada disciplina específica, inteiramente dependente metodologicamente e do ponto de vista da didática, exposta sistemática e corretamente, os alunos compreendam claramente que os fenômenos estudados e analisados por eles em uma dada disciplina, estão fortemente ligados com outros grupos de fenômenos e fatos, esclarecidos de outro

TrabalhoNecessário - www.uff.br/trabalhonecessario; Ano 11, № 17/2013. 


\section{Trabalhonecessário}

Issn: 1808 - 799X

ano 11 , no $17-2013$

ponto de vista, em outra matéria, de forma eu na consciência dos alunos cria-se a síntese dos fenômenos, a compreensão da dinâmica e interligação dos fenômenos (Pistrak apud Freitas, 2009: p. 73).

Esta metodologia será tratada mais a frente. Aqui nos interessa destacar que a Ideia hegeliana de que "a verdade é o todo" deve implicar em uma organização curricular que considere a seleção de conteúdos capazes de favorecer o reconhecimento da totalidade social e suas repercussões nas especificidades locais. Ciência, tecnologia, cultura e trabalho, por exemplo, seriam temas agregadores com força explicativa da realidade.

Essa perspectiva não exige um único elemento curricular integrador já que as formas de integração são múltiplas e dependem dos contextos e dos sujeitos envolvidos (docentes, discentes, comunidade, técnicos educacionais, gestores) e da realidade concreta (infraestrutura, tempo e recursos disponíveis). O desafio de achar "este" elemento integrador dos processos formativos é permanente, o que torna necessário a continuidade dos esforços de identificação e de sistematização destas possibilidades, propostas e experimentadas, de ensino integrado.

A opção por esta ou aquela forma de organização curricular não assegura, pó si, a integração curricular. Em sua dissertação de mestrado Costa (2012) revelou a percepção de um estudante sobre a sua experiência em um currículo organizado por eixo, em curso técnico integrado:

$\mathrm{Na}$ área técnica a gente tinha aula prática. [...] No médio a maioria tem aquela metodologia antiga de chegar e expor o assunto, aquele método tradicional da exposição e só estudar pro vestibular, ou pra cumprir o eixo temático, [...] que ensinam sem aplicabilidade. [...] Claro, há casos em que tem uma diferente metodologia, que consegue segurar o aluno na aula. (ALUNO 2, apud COSTA, 2012: p. 93 - grifo nosso). 


\section{Trabalhonecessário}

Issn: 1808 - 799X

ano 11, no $17-2013$

Do modo como colocado pelo estudante, a organização curricular por eixo, tomada por muitos como uma possibilidade de currículo integrado, serve a uma forma tradicional de ensino que compartimentaliza o fazer e o saber, o que significa que, no dizer de outro aluno: "o que a gente aprende no médio a gente aplica no técnico" (COSTA, 2012: p. 94).

Ramos (2005) sinaliza que na educação profissional a organização curricular na perspectiva da integração requer a superação das pedagogias liberais, como a Pedagogia das Competências, e recupera a noção de trabalho como princípio educativo como referência. Sob esta referência a ideia de currículo integrado deve ser compreendida como uma estratégia de articulação entre trabalho e educação, orientada pela Filosofia da Práxis, favorecendo, portanto, a integração da formação profissional à educação geral. Isso não significa, portando, que a formação geral deva ser compreendida apenas como articulação da profissionalização com a escolarização, mesmo isso sendo desejável, mas como uma utopia de uma formação inteira, que amplie o universo cultural dos educandos, em qualquer espaço ou tempo de formação.

\section{Sobre os conteúdos de ensino}

Que conteúdos são necessários para promover um trabalhador o mais amplamente formado possível? Os conteúdos de ensino também se constituem como objeto de debates entre diferentes correntes da educação. Torna-se mais ou menos importante na organização dos processos pedagógicos dependendo do projeto a que se vincula. Em nome do lema "aprender a fazer, fazendo" e da necessidade de superação das formas tradicionais de ensino, nas quais os alunos seriam "depósito de conhecimentos", os conteúdos de ensino passaram a ser questionados principalmente pelo movimento brasileiro escolanovista, 


\title{
Trabalhonecessário
}

Issn: 1808 - 799X

ano 11 , no $17-2013$

iniciado no início do século passado, que afirmava que "o mais importante não seria a aprendizagem em si, mas seu processo". Nesta perspectiva os conteúdos deveriam ser mobilizados na medida em que as necessidades fossem colocadas imediatamente e na possibilidade de desenvolvimento individual.

Sob a perspectiva da integração, a utilidade dos conteúdos não é desconsiderada, mas se considera estes não na perspectiva imediata e individual, mas da utilidade social, ou seja, os conteúdos são selecionados e organizados na medida de sua possibilidade de promover comportamentos que valorizem o ser humano e instrumentalizem o reconhecimento da essência da sociedade e a sua transformação. Procura-se, com isto, formar o indivíduo em suas múltiplas capacidades: de trabalhar, de viver coletivamente e agir autonomamente sobre a realidade, contribuindo para a construção de uma sociabilidade de fraternidade e de justiça social.

Os conteúdos de ensino são compreendidos aqui, inspirados na proposta gramsciana de escola unitária, como

\begin{abstract}
bases de conhecimentos que permitem ler, analisar, interpretar e compreender como funciona o mundo da natureza e da matéria (o que Gramsci denomina da sociedade das coisas) e como funcionam a relações sociais, políticas, culturais (sociedade dos seres humanos). Neste aspecto, a contraposição de uma escola conteudista ou não conteudista redunda numa discussão escolástica. A questão central é quais conteúdos e ao que se articulam (Frigotto, 2012: p. 08).
\end{abstract}

Sendo assim, são meios para a ampliação das capacidades humanas de intervenção sobre a realidade laboral e de intervenção social.

A organização curricular para a integração não pode abrir mão dos valores políticos próprios de uma pedagogia que se compromete com a democracia e a emancipação social dos trabalhadores, também dos componentes curriculares que promovam o desenvolvimento de habilidades 


\section{Trabalhonecessário}

Issn: 1808 - 799X

ano 11 , no $17-2013$

que revelem a autonomia dos sujeitos. Do mesmo modo não pode desconsiderar diferentes tipos de saberes: científicos, tecnológicos, técnicos e os conhecimentos populares, que permitem a intervenção humana consciente sobre a realidade.

Os saberes científicos são necessários, segundo Gramsci (1991), para assegurar aos jovens as condições para a superação das concepções mágicas e folclóricas próprias da infância. Para ele seria a ciência a base de uma escola criadora.

Machado (2009) destaca, para a educação profissional, os conhecimentos tecnológicos, que deveriam ter centralidade e que seriam as referências obrigatórias ao exercício de atividades técnicas e de trabalho. Esses saberes são compreendidos por ela não como sinônimo de técnica

Trata-se de uma ciência. Uma ciência não reduzida ao experimentalismo; uma atividade mediante a qual se produzem conhecimentos e que não se reduz a um simples reflexo dos fatos. A tecnologia é um conjunto organizado de conhecimentos e de informações, originado de diversas descobertas científicas e invenções e do emprego de diferentes métodos na produção material e simbólica (...). Tecnologia seria, portanto, a ciência da atividade humana, dos atos que produzem, adaptam ou fazem funcionar os objetos, que se revelam eficazes pela maneira mediante a qual eles fazem cumprir determinadas necessidades historicamente concretas e, assim, se tornar um padrão recomendável de ação Machado, 2009: 06).

Barato (2012) enfatiza o saber técnico e propõe a possibilidade deste ser capaz de superar a dicotomia entre teoria e prática. Para ele o saber técnico não é um "conhecimento prático", mas "uma forma particular de saber" que, fundado no fazer, reconhece que esse incorpora saberes e constitui unidade entre pensar e fazer, exigindo, por essa razão, "tratamento didático específico". Para Barato (2012), deixar de reconhecer tal especificidade é uma forma sutil de continuar a justificar a separação entre concepção e execução do trabalho.

TrabalhoNecessário - www.uff.br/trabalhonecessario; Ano 11, № 17/2013. 


\section{Trabalhonecessário}

Issn: 1808 - 799X

ano 11, no $17-2013$

Os saberes populares, aqui também considerados, são aqueles saberes que os sujeitos desenvolvem em sua prática cotidiana, que podem ser o ponto de partida para as ações formativas e podem, também, dar maior sentido aos saberes científicos, tecnológicos e técnicos.

A formação de um trabalhador desenvolvido em suas capacidades físicas e intelectuais, com capacidade de produzir e de intervir na sua realidade, capaz de transformar os seus espaços em benefício do coletivo social requer, além dos conhecimentos científicos e técnicos, outros tipos de saberes, os quais devem manter entre si uma inter-relação dinâmica em benefício da ideia de totalidade social. Deste modo, para o ensino médio e técnico, mais ainda para o ensino de jovens e adultos, é importante o reconhecimento e a consideração nas organizações curriculares da importância do conhecimento popular, que resulta de ações cotidianas, individuais e coletivas, de crenças e de interpretações pessoais, bem como dos conhecimentos tácitos do trabalhador, aqueles que são frutos do exercício do trabalho, produzido no trabalho e para o trabalho.

Se problematizados, contextualizados, articulados à realidade social, aprofundados e sistematizados, os diferentes tipos de saberes tornam-se essenciais para a concretização do desafio do ensino integrado. São estes diferentes saberes que, quando linkados uns aos outros, são compreendidos "como um sistema de relações de uma totalidade concreta" (Ramos, 2005).

Estes componentes seriam os requisitos necessários para o exercício de uma ocupação e o trabalho com eles pode favorecer mais ou menos a integração. Eles podem ser organizados por eixos, complexos, temas geradores ou demandados por projetos ou problemas. A literatura de um grupo de pesquisadores brasileiros identificados com a proposição do ensino 


\section{Trabalhonecessário}

Issn: 1808 - 799X

ano 11, no $17-2013$

integrado tem defendido a organização dos saberes em torno de quatro eixos: trabalho, ciência, cultura e tecnologia ${ }^{5}$.

Recuperamos a seguir algumas possibilidades de organização curricular com potencial de favorecer o ensino integrado. A Pedagogia da Alternância, a Pedagogia de Projetos e o Sistema por Complexos temáticos são mais do que estratégias de ensino, apesar de exigirem procedimentos didáticos específicos. A rigor são posicionamentos metodológicos que requerem e permitem o uso de diferentes procedimentos de ensino e de aprendizagem e de organização de conteúdos formativos. Neste texto, em particular, serão consideradas como objetos de disputa hegemônica e na sua possibilidade de favorecer a formação de jovens e técnicos na perspectiva dos projetos de integração de ensino.

\section{a) Organização do programa de ensino segundo os complexos temáticos}

O sistema de complexos foi proposto por Pistrak como uma possibilidade de organização da educação escolar, na União Soviética pós-revolução. Os complexos seriam temas socialmente relevantes e prenhes de significados para a vida concreta.

Pistrak (2000) recusava a denominação "método do complexo" já que seria possível trabalhar o complexo com vários métodos (excursão, laboratório etc). Mais adequado seria "método experimental ou de organização do programa de ensino segundo os complexos" (Pistrak, 2000: p. 131 - grifo nosso).

Para ele o sistema de complexos tem um conteúdo político pois deve permitir a compreensão da realidade na perspectiva marxista, ou seja, em sua dinamicidade e pelas suas relações recíprocas.

\footnotetext{
${ }^{5}$ Ver Dante Moura e Frigotto, Ciavatta e Ramos (2005).
} 


\section{Trabalhonecessário}

Issn: 1808 - 799X

ano 11, no $17-2013$

Pistrak criticava formas reducionistas de compreensão do sistema de complexos. Para ele este sistema não poderia ser entendido como ferramenta pedagógica de introdução de aplicações práticas nos estudos de uma dada disciplina, como concentração de todo um programa de ensino sobre um dado objeto ou mesmo como uma técnica metodológica de organização do programa.

O estudo da realidade por meio dos complexos requereria o método dialético como referência metodológica, devendo ser capaz de desenvolver nos alunos a capacidade de análise dialética da realidade.

A partir desta compreensão o sistema do complexo deixa de ser para nós simplesmente uma boa técnica de ensino, para ser um sistema de organização do programa justificado pelos objetivos da escola (Pistrak, 2000: p. 134 - grifos do autor).

Para sua "experimentação" Pistrak (2000) propôs algumas orientações práticas, quanto à escolha do objeto do complexo (tema do complexo), quanto à forma de se estudar cada complexo e quanto à organização do ensino médio, segundo o sistema dos complexos.

Para o pedagogo soviético, nas escolas de ensino médio o complexo não pode ser entendido como uma concentração de todas as disciplinas de ensino, em todos os momentos, em torno de um aspecto qualquer do tema dado, mas a subordinação destas disciplinas a uma única ideia, a um único objetivo para o qual tende o complexo selecionado (PISTRAK, 2000, p. 143).

Para ele seria em vão a tentativa de uma perfeita orquestração dos trabalhos de todos os docentes nas escolas de ensino médio em torno de um único tema.

TrabalhoNecessário - www.uff.br/trabalhonecessario; Ano 11, № 17/2013. 


\title{
Trabalhonecessário
}

Issn: 1808 - 799X

ano 11 , no $17-2013$

\begin{abstract}
Trata-se de um erro absoluto interpretar o sistema de complexos na escola de $2^{\circ}$ grau como uma simultaneidade perfeita do trabalho, todas as disciplinas estudando no mesmo dia e na mesma hora, durante o conjunto do trabalho, o mesmo pequeno aspecto do complexo. Um tal "encadeamento" de todo o trabalho escolar provém de uma visão simplista e leva à ideia do complexo ao absurdo. O sistema do complexo pelo complexo, o complexo concebido como um fim em si mesmo, é inútil (PISTRAK, 2000, p. 143).
\end{abstract}

Também a possibilidade de uma solução definitiva para a organização do trabalho pedagógico por meio do sistema de complexos é descartada por Pistrak. Para ele a ordem de um curso organizado a partir do sistema de complexos pode e deve ser modificada (dentro de certos limites) desde que não se abra mão do objetivo geral definido pela organização das disciplinas em complexos.

As tarefas e os objetivos de cada disciplina estariam subordinados aos objetivos gerais da escola e seriam estes objetivos que determinariam a escolha desta ou daquela disciplina.

Segundo o autor, a subordinação dos planos à concepção geral representada pelo complexo e o controle coletivo pode garantir o êxito do trabalho. Seria condições para este trabalho a ação coletiva, a solidariedade íntima entre os docentes e a subordinação dos objetivos de cada disciplina aos objetivos gerais do ensino.

Mesmo tendo dado um conjunto de orientações sobre o sistema de complexos, alertava Pistrak (2000) que as questões educacionais não poderiam ser resolvidas com a utilização deste ou daquele método e que mais importante seria a articulação do sistema dos complexos com o trabalho real dos alunos, tendo como a finalidade de promoção da autonomia destes para a atividade social prática, interna e externa à escola.

TrabalhoNecessário - www.uff.br/trabalhonecessario; Ano 11, № 17/2013. 


\section{Trabalhonecessário}

Issn: 1808 - 799X

ano 11 , no $17-2013$

\section{a) Pedagogia da Alternância}

A Pedagogia da Alternância é uma estratégia pedagógica que vem sendo cada vez utilizada no Brasil principalmente por diferentes movimentos sociais de trabalhadores do campo, como o MST - Movimento dos Trabalhadores Sem Terra. E é a articulação dos processos educativos escolares com os movimentos sociais dos trabalhadores e o seu princípio fundamental de articulação entre estudo-trabalho que identificam esta pedagogia.

Segundo Nosella (2007) a Pedagogia da Alternância caracteriza-se como uma pedagogia vocacional e não profissionalizante, a serviço dos adolescentes do meio rural, orientada pelo objetivo fundamental de mudança social, fazendo uso de um Plano de Estudo, em um ambiente educativo com pequenos grupos, tendo assegurada a participação dos pais agricultores.

Para este autor a Pedagogia da Alternância nasceu com a tarefa de enfrentar o problema colocado de que a terra é o oposto da sabedoria, da ciência, e de que ao jovem do campo que quisesse desenvolver-se intelectualmente não restaria alternativa a não ser sair em direção das cidades.

Como características que identificam a particularidade deste arranjo curricular Nosella (2007) identifica:

a) a alternância;

b) o Internato;

c) a escola articulada com a realidade social de seu meio; e

d) a organização didática por meio de um Plano de Estudo, sendo este a sua "especificidade metodológica".

A alternância e o plano de estudos não devem se orientar por uma perspectiva de instrumentalização na realidade concreta dos conteúdos 


\section{Trabalhonecessário}

Issn: 1808 - 799X

ano 11, no $17-2013$

discutidos na escola, mas pela ideia de liberdade. Sobre isto Nosella (2007: p. 20) observa que:

Note-se que o plano de Estudo jamais é uma aplicação técnico-agrícola, no sentido da escola ensinar aos alunos técnicas cada vez mais aprimoradas para ele, em seguida, aplicá-las na propriedade de sua família. O enfoque do Plano de Estudo é a conscientização: "é um compromisso dos alunos e de sua família para analisar sua própria vida".

Nosella (2007, p. 20) observa que na Pedagogia da Alternância "este aluno não é mais um aluno na escola, mas um ator num determinado contexto de vida e em um território. Sua família é convidada a participar ativamente de sua educação, de sua formação, acima de tudo porque é jovem." Portanto, é de fundamental importância a relação entre escola, aluno e comunidade para que se produzam aprendizagens que beneficiem os sujeitos e a vida em sociedade.

Nosella (2007) enfrenta um problema com o qual a Pedagogia da Alternância se defronta desde a sua origem que é a ideia de se tornar uma escola sem abertura para a cidade ou para outras formas de educação, isso pode ser percebido na função que se quer imputar a esta pedagogia, de "fixar o jovem no campo". Abbé Granereau, fundador desta proposta pedagógica, defendia uma formação rural totalmente fechada, que perfizesse todo o sistema escolar, do primário até a universidade rural (NOSELLA, 2007: p.22). Tal compreensão é incoerente com o princípio da liberdade, orientador das diferentes práticas educacionais integradoras.

Sobre isto também Pistrak (2000) nos ajuda. Ao abordar sobre o trabalho agrícola nas escolas e perceber que algumas escolas tinham suas próprias colônias e fazendas, entendia que eram um excelente tipo de organização infantil, desde que não estivessem fechadas em si mesmas, devendo permanecer abertas para o mundo exterior (PISTRAK, 2000, p. 72).

TrabalhoNecessário - www.uff.br/trabalhonecessario; Ano 11, № 17/2013. 


\section{Trabalhonecessário}

Issn: 1808 - 799X

ano 11, no $17-2013$

Apesar de ter sido desenvolvida no e para o campo, a Pedagogia da Alternância teve diferentes utilizações, em diferentes espaços, sendo modificada em seu formato. É muito utilizada na educação profissional urbana, em alternância com o ensino médio, em países como a França, a Alemanha e Chile (BARONE, 2012), tendo um exemplo bem desenvolvido dos seus princípios no sistema dual alemão (ARAUJO, 2000a, p. 238).

A Pedagogia da Alternância assumiu nas cidades a forma de ensino em que se combina escola com estágio em empresas, fugindo ao seu propósito original, que estava balizado na educação do campo. Apesar de na sua origem requerer um vínculo com os movimentos sociais, dependendo do seu uso, pode servir aos interesses de empresas, reproduzindo o modo de produção capitalista. (SANTOS, 2012).

O que Ihe pode conferir um caráter avançado, portanto, não é a garantia da articulação ensino-trabalho, mas o seu vínculo com os movimentos sociais dos trabalhadores, o que favorece a problematização da realidade e a promoção da compreensão dos fenômenos específicos em suas múltiplas relações, produzindo a autonomia dos sujeitos, finalidade do ensino integrado.

\section{b) Pedagogia de Projetos}

A pedagogia de projetos surge da necessidade de desenvolvimento de metodologias de caráter prático, que se apoiassem na atividade de aprendizagem do aluno em oposição ao modelo de ensino centrado na atividade de ensino do professor.

Tal pedagogia valoriza dois conceitos importantes:

- Conceito de aprendizagem, resgatando a sua etimologia de apoderação / tomar para si e a ênfase na ação do aluno.

TrabalhoNecessário - www.uff.br/trabalhonecessario; Ano 11, № 17/2013. 


\section{Trabalhonecessário}

Issn: 1808 - 799X

ano 11, no $17-2013$

- $\quad$ Conceito de experiência, que possibilita a validação dos conhecimentos pelo seu uso, tornando-os significativos.

Segundo o NIED-USP (2003), os Projetos de Trabalho permitem uma aprendizagem por meio da participação ativa dos educandos, vivenciando as situações-problema, refletindo sobre elas e tomando atitudes diante dos fatos. Ao educador compete resgatar as experiências do educando, auxiliá-lo na identificação de problemas, nas reflexões sobre eles e na concretização dessas reflexões em ações.

A pedagogia de projetos é um procedimento pedagógico que considera que a formação não se realiza pelas respostas dadas, mas principalmente pelas experiências proporcionadas, pelos problemas criados, pela ação desencadeada.

A proposta de uma Pedagogia de Projetos não é nova. Ela surge no início do século passado, proposta por pensadores ligados ao movimento da Pedagogia Ativa ou Progressivista (que no Brasil foi identificada com o movimento escolanovista), em particular por John Dewey, filósofo pragmático que se opunha, naquela época, às metodologias da escola tradicional que promoviam um modelo de ensino-aprendizagem centrado no professor, o qual transmitia "seus conteúdos" de maneira gradual e sequencial aos alunos, a quem cabia a assimilação passiva do que Ihes eram transmitidos.

Assumimos aqui a possibilidade de esta metodologia servir também aos objetivos do ensino integrado, para isso propomos que a Pedagogia de Projetos assuma algumas características:

1. O projeto como uma atividade intencional que deve ter objetivos claros, orientados pelo compromisso com a emancipação social. Como o envolvimento 


\section{Trabalhonecessário}

Issn: 1808 - 799X

ano 11, no $17-2013$

dos alunos é também uma necessidade do trabalho de projetos, torna-se necessário uma compreensão coletiva dos objetivos propostos.

2. Num projeto de integração a responsabilidade e a autonomia dos alunos são essenciais. Os alunos são corresponsáveis pelo trabalho e pelas escolhas ao longo do desenvolvimento do projeto. Em geral, fazem-no em equipe, motivo pelo qual a cooperação está também quase sempre associada ao trabalho.

3. Um projeto se estrutura em torno de um problema relevante socialmente e instigante, capaz de estimular o desenvolvimento da força criativa dos alunos. O problema a resolver deve ter um caráter real para os alunos, não deve servir apenas para a reprodução de conteúdos de posse do professor. O objeto central do projeto é um problema ou uma fonte geradora de problemas, que exige uma atividade prático-reflexiva para a sua resolução.

4. O projeto integrador deve ser flexível, de modo que o tempo e as condições para desenvolvê-lo sejam sempre reavaliados em função dos objetivos inicialmente propostos, dos recursos à disposição do grupo e das circunstâncias que envolvem o Projeto.

A Pedagogia de Projetos pode ser direcionada para o trabalho individual, mas revela-se mais adequada ao trabalho de um coletivo de alunos e professores, integrando diferentes tipos de tarefas e potencializando as capacidades já desenvolvidas por cada um.

Esta estratégia metodológica pode ter várias perspectivas e, a depender do enfoque dado, o projeto pode representar uma estratégia instrumental adaptadora dos seres ou pode adquirir o perfil de ação mobilizadora focalizada no processo, centrada na realidade e comprometida com a transformação (IFRN, 2012). Tanto é que instituições com projetos educacionais assumidamente com perspectivas diferentes têm utilizado a Pedagogia de Projetos como estratégia formativa prioritária, como é o caso no IFRN, que 


\section{Trabalhonecessário}

Issn: 1808 - 799X

ano 11, no 17 - 2013

assume em seu projeto pedagógico o desafio da construção do ensino integrado, e a rede de escolas do Centro Paula Souza, autarquia do Governo paulista que assume o compromisso em atender as demandas do mercado.

Pistrak (2000) propunha o desenvolvimento de projetos em situações de escola tendo estes um problema como fio condutor. Para ele um projeto deste tipo deveria a) comprovar a capacidade de os alunos vencerem as dificuldades de um problema; b) aprofundar a capacidade de usar um método e de utilizar dados teóricos; e c) Revelar a orientação do aluno em sua especialidade (PISTRAK, 2000, p. 94);

Voltamos assim, a um pressuposto deste texto, a pertinência da Pedagogia de Projetos ao projeto de ensino integrado, assim como de outros arranjos curriculares, dependeria do projeto ético-político com o qual ela esta vinculada. Assim, esta possibilidade metodológica pode ser entendida tanto numa perspectiva pragmática, utilitária, ou quanto na perspectiva do desenvolvimento amplo dos sujeitos.

$\mathrm{Na}$ perspectiva pragmática baseia-se em resultados e produtos apenas, noutra a educação baseia-se na vinculação da aprendizagem com o desafio de transformação da realidade; numa perspectiva os saberes são considerados como meras informações úteis, noutra os saberes são valorizados como conhecimentos científicos. Portanto, pode ser entendida tanto como uma metodologia de conformação dos sujeitos ao presente como uma ferramenta para a construção do futuro.

O que caracteriza o trabalho com projetos, portanto, não é a importância do assunto a ser tratado, mas o tratamento dado a esse assunto, no sentido de torná-lo uma questão do grupo como um todo e não apenas de alguns alunos ou do professor.

TrabalhoNecessário - www.uff.br/trabalhonecessario; Ano 11, № 17/2013. 


\section{Trabalhonecessário}

Issn: 1808 - 799X

ano 11, no $17-2013$

A Pedagogia de Projetos pode favorecer, assim, a ação interdisciplinar, mobilizar a força criativa de alunos e professores e promover o trabalho cooperativo. Essas são algumas das virtudes que podem favorecer a operacionalização de práticas pedagógicas integradoras.

\section{c) A educação profissional e a formação de jovens e adultos: um grande desafio de integração e a proposta do PROEJA}

Uma das especificidades metodológicas da educação profissional é determinada pelo seu público alvo, jovens e adultos, estando muitos já em exercício de alguma atividade de trabalho.

Esta condição etária e laboral exige que as práticas formativas ganhem especificidades que favoreçam as aprendizagens dos sujeitos que já têm valores arraigados, experiências e saberes acumuladas e vivência social. A educação de jovens e adultos, enquanto especificidade da educação profissional torna-se também um objeto de disputa hegemônica entre as diferentes correntes político-pedagógicas.

Tais disputas podem ser identificadas, entre outros, na centralidade do conceito que dá conteúdo a diferentes propostas. Se na ótica liberal a andragogia é um conceito central, na perspectiva integradora a Ideia de EJA assume a relevância.

\section{Educação de adultos: andragogia versus EJA}

São duas, portanto, as correntes principais que se antagonizam na educação de jovens e adultos, uma identificada com a andragogia e outra com a Educação de Jovens e Adultos - EJA, esta referenciada nos princípios da educação popular (que tem, no Brasil, Paulo Freire e Miguel Arroyo como principais referências).

TrabalhoNecessário - www.uff.br/trabalhonecessario; Ano 11, № 17/2013. 


\section{Trabalhonecessário}

Issn: 1808 - 799X

ano 11, no $17-2013$

A andragogia é a principal referência metodológica para a definição dos métodos e procedimentos didáticos, destinados a adultos, de instituições ligadas aos setores empresariais, tais como o SENAI, SENAC e alguns conglomerados empresariais como o Grupo Fiat.

Aranha (2012) entende a andragogia como uma sistematização de concepções empresariais quanto à educação de adultos, surgida da crítica as pedagogias centradas no professor e que não reconhecem os saberes dos trabalhadores.

OLIVEIRA (apud Aranha, 2012: p. 05) sistematiza o que seriam as premissas da Andragogia:

a) Necessidade de conhecer - os aprendizes adultos sabem da sua necessidade de conhecimento, bem como de colocar em prática 0 conhecimento adquirido.

b) Autoconceito de aprendiz - o adulto aprendiz é capaz de se autodesenvolver, suprindo de forma independente sua necessidade de conhecimento.

c) O papel da experiência - central na aprendizagem de adultos. "É a partir dela que ele se dispõe ou se nega a participar de algum programa de desenvolvimento."

d) Prontidão para aprender - disponibilidade do adulto para aprender o que se decidiu a aprender, baseado numa seleção natural e realista. Recusa, por parte desse adulto, de aprender o que lhes impõem.

e) Orientação para a aprendizagem - significado prático da aprendizagem para 0 adulto, diferente de uma mera retenção de conhecimentos.

f) Motivação - baseada na própria vontade de crescimento do adulto (motivação interna) e não em estímulos externos "vindos de outras pessoas, como notas de professores, avaliação escolar, promoção hierárquica, opiniões de superiores, pressão de comandos, etc". 


\section{Trabalhonecessário}

Issn: 1808 - 799X

ano 11, no $17-2013$

Evidenciando o caráter conservador desta proposta, Aranha (2012) argumenta que existem várias similitudes entre a andragogia e as pedagogias das competências e a da qualidade total, de conteúdo libera:

O apoio não a qualquer conhecimento, mas ao conhecimento prático, instrumental; o apelo à participação e independência do trabalhadoraprendiz; o reforço à comunicação como mecanismo essencial do processo de aprendizagem; a valorização do conhecimento prévio do trabalhador (experiência de vida), entre outros (Aranha, 2012: p. 06 Grifo nosso).

Nessa perspectiva de educação de adultos a figura do professor é questionada e, em seu lugar, é proposta a figura do facilitador. Aranha (2012) conclui que a andragogia constituiu-se com mais um instrumento de adequação dos trabalhadores ao ideário das empresas.

Para esta pesquisadora, com base em Miguel Arroyo, é a educação de adultos, na perspectiva da educação popular, que deve propiciar ao trabalhador o acesso ao saber socialmente construído com a garantia da educação básica, profissional e sindical.

(Miguel Arroyo) parte do pressuposto de que grande parte dos trabalhadores teve uma deficiente formação básica e, portanto, pouco acesso ao patrimônio cultural da humanidade. Uma educação profissional que não leve em conta esse aspecto tende a cair na instrumentalização da educação, no pragmatismo educacional (Aranha, 2012: 09).

Outra referência importante no campo da EJA é Álvaro Vieira Pinto (PINTO, 2003). Para ele a educação de adultos seria a fase mais rica da existência humana, pois permitiria o pleno desenvolvimento das suas potencialidades por meio da articulação da realidade do trabalhador com 0 


\section{Trabalhonecessário}

Issn: 1808 - 799X

ano 11, no $17-2013$

conjunto de conhecimentos básicos (com significados reais) que precisa assimilar. Para isso seriam necessárias estratégias formativas que considerassem o educando como detentor de saberes e como sujeitos da educação, "nunca objeto" dela, já que essa deve se materializar como um diálogo amistoso entre sujeitos com experiências diferenciadas.

Pinto (2003) identificava como componentes diferenciadores da EJA a compreensão do contexto social em que estão inseridos os sujeitos e a finalidade de mudança da condição humana do indivíduo, alterando o ser do homem em direção a sua autonomia.

Aranha (2012: p. 09) sintetiza algumas orientações para a educação de adultos, na perspectiva da educação popular:

a) Considerar os saberes que os adultos já têm.

b) Considerar a possibilidade de diferentes tempos de aprendizagem e de espaços formativos como o trabalho, a militância etc.

c) Ter flexibilidade para mudar o processo durante o andamento dos cursos, de acordo com os anseios e necessidades do coletivo de professores e alunos.

d) Considerar que o processo de aprendizagem não é meramente racional; aprende-se com o desenvolvimento da sensibilidade, da percepção.

e) Estabelecer a avaliação como um processo reflexivo e não como uma ação punitiva.

f) Valorizar a origem, a história e a cultura dos alunos, "necessárias para a construção de sua identidade e ampliação de sua formação". (LEITE, 1996).

g) Considerar que a formação incompletude e continuidade da formação docente

Se aparentemente as proposições da andragogia e da EJA se assemelham, entre elas há uma diferença fundamental: o caráter instrumental, imediatista e fragmentado que assume a formação na perspectiva da andragogia, em contraposição a perspectiva de uma aprendizagem ampla, capaz de permitir acesso ao saber científico e de dar aos alunos trabalhadores 


\section{Trabalhonecessário}

Issn: 1808 - 799X

ano 11 , no $17-2013$

condições para construírem sua autonomia e de se encontrarem como sujeitos sociais, presentes nas finalidades da EJA.

Se na andragogia "tudo é absolutamente dirigido e racionalizado", na EJA são necessárias mudanças de percursos em função das alterações na realidade concreta de realização dos cursos e de demandas e aspirações dos educandos.

Aranha (2012), ao concluir sobre os resultados de uma pesquisa feita na FIAT, afirma que

Longe de absorver as reflexões e avanços pedagógicos já feitos no campo educacional sobre a educação de adultos, em especial de adultos trabalhadores, a Andragogia trabalhada pela Fiat, compõe-se mais de um conjunto de definições e metodologias, com forte influência dos esquemas organizativos atuais e marcado pelo imediatismo no que deve ser trabalho, com uma visão restrita do processo educacional e da educação como um todo (Aranha, 2012: 13).

Assim, tal como as diferentes possibilidades de organização didática, as diferentes formas de trabalho pedagógico com adultos, na possibilidade de sua efetividade integradora, requer o compromisso ético-político com a cultura do trabalho e o projeto de construção de uma sociedade dos trabalhadores. Parafraseando Pinto (2003), o que distingue a educação de adultos não é o conteúdo, os métodos, as técnicas de instruir, mas sim os motivos e os interesses que se tem quando se realiza o trabalho educativo.

TrabalhoNecessário - www.uff.br/trabalhonecessario; Ano 11, № 17/2013. 


\section{Trabalhonecessário}

Issn: 1808 - 799X

ano 11 , no $17-2013$

\section{Considerações:}

Tentamos evidenciar neste artigo que são várias as possibilidades de arranjos pedagógicos e curriculares para o ensino integrado e que são diferenciados os elementos de integração do ensino e da aprendizagem, mas também que decisivo é o compromisso docente com as ideias de formação integrada e de transformação social.

O tratamento que procuramos dar às diferentes possibilidades metodológicas para um trabalho pedagógico integrador procurou combinar os elementos que consideramos essenciais para o desenvolvimento de práticas pedagógicas integradoras: a valorização da atividade transformadora de docentes e discentes, a preferência por estratégias que fortaleçam os coletivos, o compromisso com a possibilidade de compreensão ampla dos alunos e professores dos fenômenos específicos, em sua relação com a realidade, e a busca pela articulação das práticas pedagógicas com o seu contexto social e com as organizações de trabalhadores.

As diferentes metodologias consideradas no texto, potencialmente coerentes com o projeto de ensino integrado, requerem procedimentos específicos que também a materializem, algumas delas foram tratadas aqui seguir, sempre consideradas a parti de dois pressupostos: a) qualquer procedimento ou técnica de ensino e de aprendizagem, apesar de ter história e marcas pelos usos sociais, não é previamente comprometido com a integração ou com a fragmentação do saber. Decisiva, para a possibilidade de integração, como já dissemos, é o compromisso de educadores e instituições com o projeto de emancipação social; e b) também cada instrumento pode ser entendidos como objeto de disputa hegemônica entre as diferentes pedagogias.

TrabalhoNecessário - www.uff.br/trabalhonecessario; Ano 11, № 17/2013. 


\section{Trabalhonecessário}

Issn: 1808 - 799X

ano 11 , no $17-2013$

São muitas as possibilidades de integração curricular, no entanto, uma condição básica para isto é o diálogo entre as áreas do conhecimento, entre os atores envolvidos e entre as experiências em curso. Sem isso o planejamento, a execução e o acompanhamento destas atividades redundarão num esvaziamento de seu conteúdo avançado, fazendo com que sua experimentação seja meramente formal (não essencial). Ou seja, para a integração curricular torna-se necessária a criação de uma nova cultura escolar, de diálogo e de democracia, requer também o convencimento dos profissionais envolvidos e requer por parte destes a apropriação dos conceitos e princípios do Ensino Médio Integrado, sem o que a ideia de currículo integrado pode se configurar apenas como um emblema da mesmice pedagógica. 


\section{Trabalhonecessário}

Issn: 1808 - 799X

ano 11, no $17-2013$

\section{REFERÊNCIAS:}

ARANHA, Antônia Vitória soares. Andragogia: avanço pedagógico ou pedagogia de resultados na educação profissional de alunos adultos/trabalhadores? In: www.anped.org/reunioes/24/t18739227705492.doc. Acessado em 19/10/2012.

ARAUJO, Ronaldo Marcos de Lima. Avaliação por competência. In: Fidalgo, Fernando e MACHADO, Lucília (editores). Dicionário da Educação Profissional. Belo Horizonte: NETE, 2000.

Desenvolvimento de Competências Profissionais: as incoerências de um discurso. Tese de doutoramento defendida no PPGED da Universidade Federal de Minas Gerais. Belo Horizonte: 2001.

Instituições de Formação Profissional História e Perspectivas: o projeto da nova institucionalidade da educação profissional brasileira dos anos 1990. In: V Colóquio de Pesquisa Sobre Instituições Escolares: Entre o Individual e o Coletivo (anais). São Paulo: Editora da Uninove, 2008.

BARATO, Jarbas Novelino. Em Busca de uma Didática para o Saber Técnico. In: HTTP://www.senac.br/BTS/252/boltec252d.htm. Acessado em 19/11/2012.

BARONE, Rosa Elisa M. Formação Profissional: uma contribuição para o debate brasileiro contemporâneo a partir da experiência internacional. In: HTTP://www.senac.br/BTS/241/boltec241b.htm.Acessado em 20/11/2012.

BIANCHETTI, Lucídio et all. Interdisciplinaridade. Petrópolis: Vozes, 1995. CUNHA, Luiz Antonio. 0 ensino profissional na irradiação do industrialismo. São Paulo: Unesp; Brasília: Flacso, 2005.

DEWEY, Jonh. Democracia e Educação. São Paulo, Companhia editora Nacional, 1936.

BRASIL / Ministério da Educação. Ensino Médio Integral: construindo a política para todos no Brasil. Versão Preliminar - circulação Restrita. Texto: Brasília, 2013. 


\section{Trabalhonecessário}

Issn: 1808 - 799X

ano 11, no $17-2013$

COSTA, Ana Maria Raiol da. Integração do Ensino Médio e Técnico: percepçãoe de alunos do Instituto Federal de Educação, Ciência e Tecnologia do Pará - IFPA/Campus Castanhal. Dissertação de Mestrado defendida no Programa de Pós-Graduação em Educação da UFPA. Belém, 2012.

FREITAS, Luiz Carlos. A Luta por uma Pedagogia do Meio: revisitando o conceito. In: PISTRAK (Org.) A Escola-Comuna. São Paulo: Expressão Popular, 2009.

FRIGOTTO, Gaudêncio. Qualidade e Quantidade da Educação básica no Brasil: Concepções e materialidade. Rio de Janeiro: Texto impresso. 2012.

FRIGOTTO, Gaudêncio; CIAVATTA, Maria; RAMOS, Marise. FRIGOTTO, Gaudêncio; CIAVATTA, Maria; RAMOS, Marise. Ensino Médio Integrado: concepções e contradições. São Paulo: Cortez, 2005.

GADOTTI, Moacir. Concepção Dialética da Educação. 8 ed. São Paulo: Cortez, 1992.

GRAMSCI. Antonio. Organização da escola e da cultura. In: Os intelectuais e a organização da cultura. Ed. Cortez, São Paulo, 1991.

HERNANDEZ, F. \& VENTURA, M. A Organização de Currículo por Projetos de Trabalho. Porto Alegre: Artmed, 1998.

HOTZ, Karina Griggio. Avaliação da implementação do PROEJA em municípios do Oeste do Paraná (2008-2009). Dissertação de Mestrado defendida no Programa de Pós-Graduação em Educação da Unioeste. Cascavel (PR), 2010.

IFRN. Projeto Político-Pedagógico do IFRN: uma construção coletiva DOCUMENTO BASE - Versão para consulta pública à comunidade acadêmica do IFRN. Natal-RN, IFRN, 2012.

MACHADO, Lucília Regina de Souza. PROEJA: o significado socioeconômico e o desafio da construção de um currículo inovador. In: Proeja: formação técnica integrada ao ensino médio. Brasília: MEC, 2006.

- Ensino médio e técnico com currículos integrados: propostas de ação didática para uma relação não fantasiosa. In: 


\section{Trabalhonecessário}

Issn: 1808 - 799X

ano 11 , no $17-2013$

JAQUELINE MOLL \& colaboradores. (Org.) Educação Profissional e Tecnológica no Brasil Contemporâneo: desafios, tensões e possibilidades. 1a Ed. Porto Alegre, RS: ARTMED Editora S.A., 2009.

NIED - NÚCLEO DE Informática Aplicada à Educação da UNICAMP Universidade Estadual de Campinas. Disponível em HTTP://www.cdisp.org.br/pedagogoco/projeto/. Acessado em 12/02/2003.

NOSELLA, Paolo. Origens da Pedagogia da Alternância. Brasília, 2007.

PINTO, Álvaro Vieira. Sete Lições Sobre Educação de Adultos. São Paulo: Cortez/Autores Associados, 2003.

PISTRAK (org.). A Escola-Comuna. São Paulo: Expressão Popular, 2009.

Popular, 2000. Fundamentos da Escola do Trabalho. São Paulo: Expressão

RAMOS, Marise. Possibilidade e desafios na organização do currículo integrado. In: FRIGOTTO, G; CIAVATTA, M; RAMOS, M. Ensino Médio Integrado: concepções e contradições. São Paulo: Cortez, 2005.

SANTOMÉ, Jurjo Torres. Globalização e Interdisciplinaridade: o currículo integrado. Porto Alegre: Artes Médicas, 1998.

SANTOS, Manuela Tavares. A Pedagogia da Alternância como Método de Integração de Saberes no Proeja Quilombola no Instituto Federal do Pará (IFPA) - Campus Castanhal. Texto apresentado para exame de qualificação. Belém. Programa de Pós-Graduação em Educação da Universidade Federal do Pará, 2012.

SANTOS, Rosineide de Belém Lourinho dos. Esboços de Leonardos: A Experiência da Forma Integrada de Ensino Profissional do CEFET-PA. Dissertação submetida ao Mestrado Acadêmico em Educação da Universidade Federal do Pará. Belém - Pará. 2008

SILVA, Tomaz Tadeu; MOREIRA, Antônio Flávio. Currículo, Cultura e Sociedade. São Paulo: Cortez, 2005.

TIRIBA, Lia Vargas e SANT'ANNA, Gilson Carlos. Quem tem medo dos conteúdos educacionais?

In: 


\section{Trabalhonecessário}

Issn: 1808 - 799X

ano 11 , no $17-2013$

HTTP://grabois.org.br/portal/cdm/revista.int.php?id_sessao=50\&id_publicacao= 97\&id-indice=252.Publicado em 01.08.19985. Acessado em 06/11/2012.

VÁZQUEZ, Adolfo Sánchez. Filosofia da Práxis. Rio de Janeiro: Paz e Terra, 1968.

Data de recebimento: 30/09/2013

Data de aprovação: 20/12/2013

TrabalhoNecessário - www.uff.br/trabalhonecessario; Ano 11, № 17/2013. 